\title{
In response to: anesthesia for minimally invasive cardiac surgery: is it still a place for opioids?
}

\author{
Chinmay Patvardhan, Florian Falter \\ Department of Anaesthesia and Intensive Care, Royal Papworth Hospital, Cambridge, UK \\ Correspondence to: Florian Falter, MD, FRCA, FFICM, PhD, Consultant in Anaesthesia. Department of Anaesthesia and Intensive Care, Royal \\ Papworth Hospital, CB2 0AY Cambridge, UK. Email: florian.falter@gmail.com. \\ Comment on: Sarridou DG, Boutou A, Mouratoglou SA. Anesthesia for minimally invasive cardiac surgery: is it still a place for opioids? J Thorac Dis \\ 2021. doi: 10.21037/jtd-21-910.
}

Submitted Jun 22, 2021. Accepted for publication Jul 02, 2021.

doi: 10.21037/jtd-2021-35

View this article at: https://dx.doi.org/10.21037/jtd-2021-35

We thank Sarridou and colleagues for their interest in our article about anesthesia for minimally invasive cardiac surgery and appreciate the comments made in their letter.

We agree that years of patient experience confirm that the use of low dose fentanyl/alfentanil infusions, with the addition of low-dose ketamine, can provide effective analgesia and cannot be considered inferior to epidural analgesia. However, despite clinical trials showing noninferiority, a significant proportion of patients continue to experience opioid related side effects in practice-commonly delirium, respiratory depression, nausea and vomiting, oversedation and poor mobilizing after surgery. Ten percent of cardiac surgical patients have recently been shown to progress to persistent opioid use 3-6 months postoperatively when prescribed regular opioid analgesia on discharge (1).

We agree that thoracic wall blocks like Serratus plane block or erector spinae blocks can be used effectively in many patients. However, pain after cardiothoracic surgery is multifactorial. Pain and the inability to mobilize or do respiratory exercises related to an intercostal drain requires different interventions than that caused by pleural inflammation. Chest wall blocks may not always be sufficient to provide effective analgesia on their own and a thoracic epidural still has its role here, especially in patients with complex pain issues and those with borderline respiratory function. In addition, thoracic epidural analgesia has been shown to be associated with reduced mortality and appears to be safe with a hematoma rate of 1:3,552 (2).

We believe that all the modalities mentioned by the authors and in our paper have their place in clinical practice. Recently, published guidance by the British Pain Society sums it up succinctly: 'Goals of pain management must be matched to the type of surgery and to the stage of recovery' (3). In other words, in early stages after cardiac surgery the goal is to facilitate early, assisted mobilization and respiratory function and in later stages increasingly independent mobilization. We believe that opioid sparing or opioid free techniques are better suited for minimally invasive surgery but agree with Sarridou et al. that an analgesic regimen should be tailored to individual patients' needs and institutional practice. We have previously demonstrated a trend towards faster recovery and comparable efficacy of an opioid free anesthetic technique after thoracic surgery for lung cancer when compared with standard morphine-based analgesia (4). In our institution we have experience with performing both minimally as well as standard cardiac and thoracic surgery with a completely opioid free anesthetic technique. As surgical technique evolves, we believe that analgesia must evolve along with it to provide an effective and safe perioperative environment for patients.

\section{Acknowledgments}

Funding: None.

\section{Footnote}

Provenance and Peer Review: This article was commissioned 
by the editorial office, Fournal of Thoracic Disease. The article did not undergo external peer review.

Conflicts of Interest: Both authors have completed the ICMJE uniform disclosure form (available at https://dx.doi. org/10.21037/jtd-2021-35). Both authors have no conflicts of interest to declare.

Ethical Statement: The authors are accountable for all aspects of the work in ensuring that questions related to the accuracy or integrity of any part of the work are appropriately investigated and resolved.

Open Access Statement: This is an Open Access article distributed in accordance with the Creative Commons Attribution-NonCommercial-NoDerivs 4.0 International License (CC BY-NC-ND 4.0), which permits the noncommercial replication and distribution of the article with the strict proviso that no changes or edits are made and the original work is properly cited (including links to both the formal publication through the relevant DOI and the license). See: https://creativecommons.org/licenses/by-nc-nd/4.0/.

\section{References}

1. Brown CR, Chen Z, Khurshan F, et al. Development of Persistent Opioid Use After Cardiac Surgery. JAMA Cardiol 2020;5:889-96.

2. Landoni G, Isella F, Greco M, et al. Benefits and risks of epidural analgesia in cardiac surgery. Br J Anaesth 2015;115:25-32.

3. Srivastava D, Hill S, Carty S, et al. Surgery and opioids: evidence-based expert consensus guidelines on the perioperative use of opioids in the United Kingdom. Br J Anaesth 2021;126:1208-16.

4. Devine G, Cheng M, Martinez G, et al. Opioid-Free Anesthesia for Lung Cancer Resection: A Case-Control Study. J Cardiothorac Vasc Anesth 2020;34:3036-40.

Cite this article as: Patvardhan $\mathrm{C}$, Falter F. In response to: anesthesia for minimally invasive cardiac surgery: is it still a place for opioids? J Thorac Dis 2021;13(8):5113-5114. doi: $10.21037 /$ jtd-2021-35 